\title{
Aspirin plus dipyridamole was more effective than aspirin alone for preventing vascular events after minor cerebral ischaemia
}

Halkes PH, van Gijn J, Kappelle U, et al. Aspirin plus dipyridamole versus aspirin alone after cerebral ischaemia of arterial origin (ESPRIT): randomised controlled trial. Lancet 2006;367:1665-73.

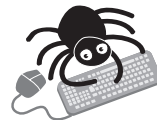

This article contains extra text on the EBM

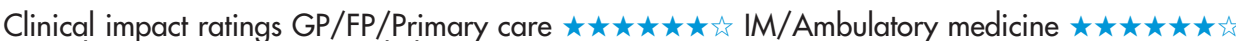
website

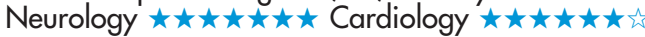

In patients with recent minor cerebral ischaemia of arterial origin, is aspirin plus dipyridamole (ASA+DP) more effective than aspirin (ASA) alone for preventing vascular events?

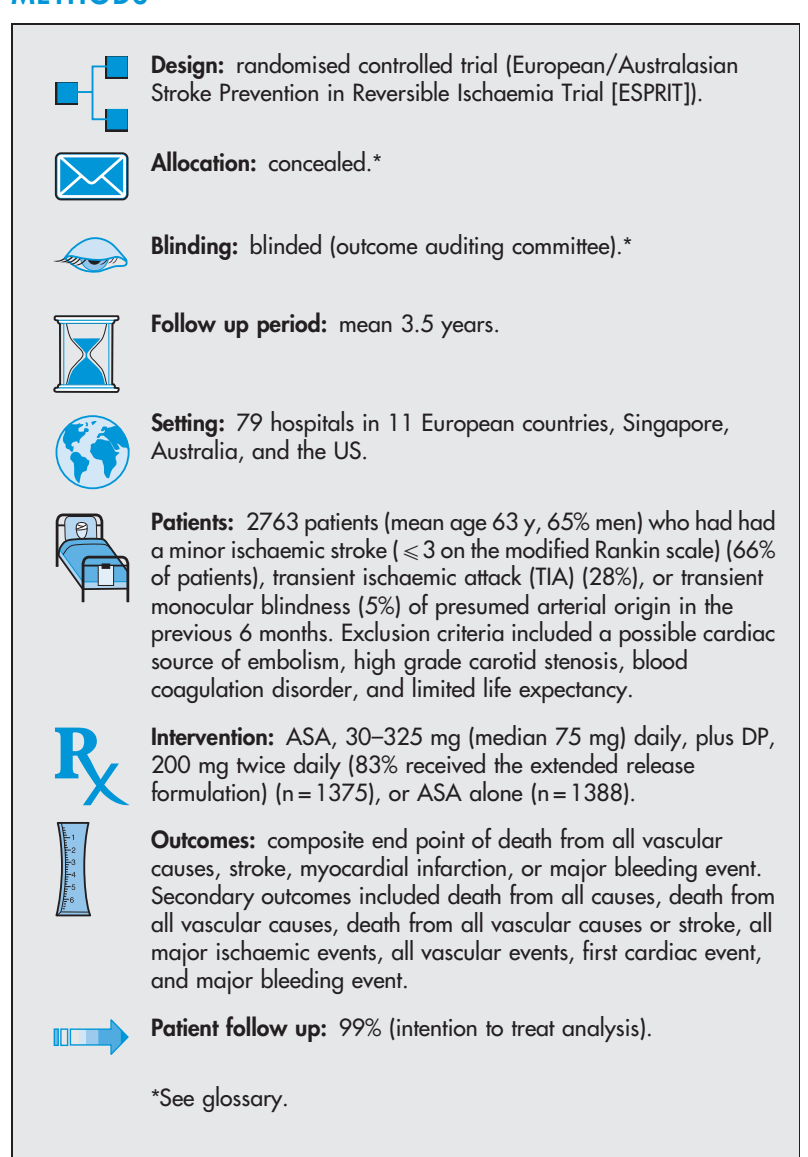

\section{MAIN RESULTS}

Risks of the composite end point, death from all vascular causes or nonfatal stroke, and all vascular events were lower in the ASA+DP group (table). Groups did not differ for death from all causes, death from all vascular causes, all major ischaemic events, first cardiac event, or major bleeding event (see table at www.evidence-basedmedicine.com). 34\% of patients in the ASA+DP group discontinued the study medication compared with $13 \%$ in the ASA group.

\section{CONCLUSION}

In patients with recent minor cerebral ischaemia of arterial origin, the combination of aspirin and dipyridamole was more effective than aspirin alone for preventing vascular events.

For correspondence: Professor A Algra, University Medical Center Utrecht Utrecht, The Netherlands. a.algra@umcutrecht.nl

Sources of funding: Council of Singapore; European Commission; Janivo Foundation; French Ministry of Health; Netherlands Heart Foundation; Netherlands Thrombosis Foundation; UK Stroke Association.
Abstract and commentary also appear in ACP Journal Club.

Commentary

- SPRIT is the second randomised trial to show the superiority of ASA+DP over ASA in patients with TIA or minor ischaemic stroke. This should lead to greater confidence in the effectiveness of ASA+DP over ASA and more patients being treated with this combination. However, the number needed to treat of 104 per year to prevent 1 primary outcome suggests a small absolute benefit; cost effectiveness will be a factor in many settings. If cost remains a concern, ASA alone or combined with generic DP is a reasonable alternative. ${ }^{1}$

Patients with a possible cardiac source of embolism or significant carotid disease were excluded from this study and the results cannot be generalised to them. Patients with disabling stroke were also excluded; ASA+DP may not be cost effective compared with ASA in such patients. ${ }^{2}$ Since most ESPRIT patients were randomised 1-6 months after TIA or stroke, the study does not address the matter of the best antiplatelet agent for acute stroke treatment. The non-blinding of patients and clinicians and the finding of less benefit in the "on treatment" analysis potentially undermine the validity of the main study findings.

The use of ASA+DP in patients with comorbid ischaemic heart disease has been debated. In neither trial comparing ASA+DP with ASA was the risk of cardiac events increased with ASA+DP. However, guidelines recommend against using DP for patients with chronic stable angina and advocate the combination of ASA and clopidogrel for patients with unstable angina or myocardial infarction..$^{3-4}$

Aggressive management of blood pressure, cholesterol, diabetes, tobacco use, and exercise further reduces risk of recurrence after ischaemic stroke. Combined with appropriate use of ASA+DP or other antithrombotic agents, this multimodal approach should effectively reduce vascular risk. David Tirschwell, MD, MSc Harborview Medical Center, Seattle, Washington, USA

1 Jonas S, Grieco G. Cerebrovasc Dis 2006;22: 1-3.

2 Jones L, Griffin S, Palmer S, et al. Health Technol Assess 2004;8(38): 1-196. 3 Gibbons RJ, Abrams J, Chatteriee K, et al. Circulation 2003;107:149-58.

4 Antman EM, Anbe DT, Armstrong PW, et al. Circulation 2004; 1 10:588-636.

Aspirin plus dipyridamole $v$ aspirin alone to prevent vascular events after minor cerebral ischaemia*

\begin{tabular}{lllll}
$\begin{array}{l}\text { Outcomes at } \\
\text { mean } 3.5 \text { years }\end{array}$ & $\begin{array}{l}\text { Aspirin }+ \\
\text { dipyridamole }\end{array}$ & $\begin{array}{l}\text { Aspirin } \\
\text { alone }\end{array}$ & RRR (95\% CI) & NNT (CI) \\
\hline $\begin{array}{l}\text { Composite end } \\
\text { pointt }\end{array}$ & $13 \%$ & $16 \%$ & $19 \%(2$ to 32$)$ & 35 (20 to 347$)$ \\
$\begin{array}{l}\text { Death from all } \\
\text { vascular causes } \\
\text { or stroke } \\
\text { All vascular events }\end{array}$ & $11 \%$ & $12 \%$ & $21 \%(3$ to 36$)$ & 39 (23 to 287) \\
\end{tabular}

*Abbreviations defined in glossary; RRR, NNT, and Cl calculated from hazard ratios in article. †Death from all vascular causes, stroke, myocardial infarction, or major bleeding event. 